\title{
Studies on the Backward Transfer of Interlanguage Syntactic Structure-Taking Temporal Adverbial Clause as an Example
}

\author{
Chen Yuan \\ School of Humanities and Social Sciences, Hei Longjiang Bayi Agricultural University, Daqing City, Hei Longjiang \\ 163319 P. R. China
}

\begin{abstract}
The research focuses on the language transfer in $\mathrm{L} 2$ and $\mathrm{L1}$ environment. The paper explores the language backward transfer from L2 (English) to L1 (Chinese) for mainland Chinese students in Australia as well as in China. With long time scholars concentrated on the forward transfer from L1 to L2 and profited a lot. However, there is some evidence reflected that backward transfer from L2 to L1 may take place in L2 and L1 environment, even in some academic occasion, L1 syntactic rules are losing. In this study, participants are mainland Chinese undergraduates from University of Newcastle and Hei Longjiang Bayi Agricultural University to complete translation and writing tasks. The aim of the paper is to investigate whether the backward transfer occurs in sentence translation and discourse level and the relationship between the backward transfer and L2 proficiency. The expected results are that backward transfer can happen both in L2 and $L 1$ environment and the higher L2 proficiency can decrease backward transfer. In view of this, the research can reflect the complexity of language backward transfer and the relationship with L2 proficiency.
\end{abstract}

Index Terms - language transfer, backward transfer, contrastive research, L2 proficiency

\section{INTRODUCTION}

The influence of mother tongue on second language is a core area in the study of second language acquisition. Odlin (1989) claimed that one of the major issues in the field of Second Language Acquisition (SLA) is the role of language learners' first language (L1) in the acquisition of a second language (L2), which SLA literature has shown extensive research on. Ulrich Weinreich (1953) talked about interference as "those instances of deviation from the norms of either language which occur in the speech of bilinguals as a result of their familiarity with more than one language" (p.14), which was later, called "language transfer. Odlin (1989) offered his "working definition" of transfer as is the influence resulting from the similarities and differences between the target language and any other language that has been previously (and perhaps imperfectly) acquired" (p.17). In addition, Odlin (1989) concluded that transfer occurs both in informal and formal contexts. The evidence for transfer comes not only from second language investigations in school settings but also from naturalistic studies of individuals who have acquired what they know of a second language without any schooling (p.152). He also claimed that most of the language transfer research discussed in the background of acquisition of European languages, especially English. He encouraged more studies can be focused on target languages with very different typological properties. Jacquelyn Schachter (1992) argued that transfer is not a process at all, and is in fact a misnamed phenomenon - an unnecessary carryover from the heyday of behaviorism. They also argued that the process of transfer is more appropriately viewed as evidence of a constraint on the learner's hypothesis testing process. In other words, the notion of transfer as a process is replaced by the notion of transfer as a constraint imposed by previous knowledge on a more general process, that of inferencing. Odlin (1989) indicated that previous knowledge is expanded as the basis from which one infers the domain from which the correct hypothesis will be taken to account for new data. And the previous knowledge includes L1 knowledge and also the learner's conceptualization of the target language. What is discussed above is the definition and development of language transfer. Next the classification of language transfer is shown. In terms of classification of transfer, from the effectiveness perspective, language transfer can be divided into positive transfer which means the native-target languages are identical or similar and negative transfer which means the native-target languages are different. From the direction perspective, language transfer can be divided into forward transfer and backward transfer. The former one is that the known languages transfer to target one, the latter is the opposite direction. During the following 50 years, great researches have been done on Second Language Acquisition and Second Language Application from view of forward transfer. Yet few people seemed to notice that Weinreich's and Odlin's definitions concerned deviation from either language. Brown (2000), Su (2001) and Cook (2003) showed that the term transfer implies more than simply the effects of the L1 on the L2; the L2 also influences the L1.The effects of the second language on the first, sometimes called "reverse" or "backward" transfer.

\section{PReVious STUdies ON BACKWARD TRANSFER}


Recent years has witnessed a growing interest in L2 effect. Researchers approach this phenomenon from different perspectives: phonology (Major, 1992), lexical semantics (Dewaele \& Pavlenko, 2003; Laufer, 2003; Pavlenko, 2003; Ramírez, 2003), morphosyntax (Balcom, 1997; Pavlenko, 2003; Ramírez, 2003), sentence processing (Cook, et al., 2003; Su, 2001), and pragmatics (Cenoz, 2003; Valdes \& Pino, 1981; Su, 2004). Schmidt (1995) revealed that Australian aboriginal language can be found some marks from English transfer. Sarason(1999) claimed that L1 (Spanish)-L2 (English) students made more use of pronouns in quantity. Cook (2003), for example, published a collection of articles addressing the issue of "Effects of the Second Language on the First", to use the name of his book. Moreover, Carson and Kubanyiova (1994) investigate Chinese students across three English proficiency levels who wrote in L1 Chinese and L2 English in U.S. pre-academic intensive English programs, universities, and graduate schools. Carson and Kubanyiova (1994) argued that L1 Chinese writing proficiency declined as L2 English writing proficiency increased. Fred Jyun-gwang Chen (2006) conducted the bidirectional transfer between English and Chinese in the case of Chinese ESL learners in US, this study was carried out from Taiwanese perspective, not mainland China.

All in all, little research has been made from L2 effect on L1 within L2 and L1 environment on sentence translation and discourse level, even less effort can be made on backward transfer of interlanguage from mainland Chinese in L2 environment. Due to various reasons, the situation can be quite different in mainland China, for example, economic, historical, educational background and geographical differences, etc. Therefore, the purpose of this paper is to investigate whether the backward transfer occurs in sentence translation and discourse level and the relationship between the backward transfer and L2 proficiency. Specifically, the investigation will be made in terms of the question of the impact of English temporal adverbial clauses on Chinese ones. Moreover, if it was found to occur, to what extent is backward transfer related to learners' L2 English proficiency?

\section{THEORETICAL FRAMEWORK}

The term multi-competence was firstly introduced by Cook to refer to "knowledge of two or more languages in one mind"'(Cook, 2003, p.2). It encompasses bilinguals' knowledge of both the first language and the second one. This distinctive compound state of mind is not equivalent to two monolingual states and thus L2 users are unique in their own right (Cook, 2003, p.124). In this light, cross-linguistic influence is a preferred term than transfer, and L2 users than L2 learner. In addition, Cook (2002) mentioned that "clearly neither total separation nor total integration can be completely true". Thus, the two languages are in an integration continuum in the minds of Chinese learners of English. The two languages can affect mutually in bi-directions more or less. To some degree Chinese output of English users can be influenced by their English. On the other hand, considering the temporal adverbial clause with zai...zhiqian(before), zai..zhihou(after) and dang...shi(when/while), this type of influence is called restructuring transfer. To some extent, EFL users restructure their English to violate some syntactic rules in Chinese.

However, interlanguage theory needs to be illustrated before restructuring in this paper. Selinker (1972) coined this term which is used to refer to both the internal system that a learner has constructed at a single point in time (an interlanguage) and to the series of interconnected systems that characterize the learner's progress over time (interlanguage or the interlanguage continuum). So as to enhance skills learning for second language, McLaughlin (1987) proposed information processing model. It reflected that information-processing capacity can be extended through restructuring. Restructuring can bring about qualitative changes in learners' interlanguage and these changes relate to both the way knowledge is represented in the minds of learners and also the strategies they employ (McLaughlin, 1987, p. 212). The primary mechanism of restructuring is automatization. McLaughlin (1987) claimed that "once procedures at any phase become automatized...learners step up to a "meta-procedural" level which generates representational change and restructuring' (p.138). That is to say, restructuring involves the replacement of existing procedures with more efficient ones.

In addition, the paper studies on two types of language environment---L2 (English) and L1 (Chinese). There are two kinds of contexts or settings in which learning takes place---natural and educational settings. The former arise in the course of the learners' contact with other speakers of the L2 in a variety of situations. In natural settings, informal learning occurs. That is, learning is considered to result from direct participation and observation without any articulation of the underlying principles or rules (Scribner \& Cole, 1973). In contrast, formal learning is held to take place through conscious attention to rules and principles and greater emphasis is placed on mastery of subject matter treated as a decontextualized body of knowledge (Scribner \& Cole, 1973). The mainland Chinese undergraduates in UoN are involved into both natural and educational settings. They can learn English out of classroom for communication purpose, in addition to language classroom (named language center) for academy. However, for mainland Chinese undergraduates in Hei Longjiang bayi Agricultural University, they are mostly involved into educational settings. Ellis (2010) claimed although the potential exists for natural discourse to occur in the classroom, studies show that it seldom does. Language classroom, Ellis (2010) defined it as a setting where the target language is taught as a subject only and is not commonly used as a medium of communication outside the classroom. So the proficiency of L2 for mainland Chinese undergraduates in Hei Longjiang bayi Agricultural University mainly originated from educational settings. 
The study sets out to examine the L2 effect of English on mainland Chinese EFL users' L1 on the sentence translation and discourse level, with a focus on their use of temporal adverbial clause. It seeks to answer the following questions: 1) Does their L2 have any effect on their L1 when the mainland Chinese EFL users are making temporal adverbial clause in their L1?

2) If indeed, does their L2 English proficiency have any effect on the degree of their L1 Chinese and if does, how does their L2 English proficiency level relate to backward transfer?

\section{RESEARCH FOUNDATION}

\section{A. Linguistic Pattern under Research}

Temporal adverbial clause belongs to a complex sentence, which is generally composed of subordinate clause and main clause. Wang (1984) covered that subordinate clause is at the beginning and the main clause is at last.

1) Dang wo jia che de shihou, wo buneng he renheren tanhua.

When I drive car, I cannot with anyone talk.

2) When I'm driving, I can't talk with anyone.

3) I can't talk with anyone when I'm driving.

As we can see, example1 is a Chinese temporal adverbial clause in which the conjunction Dang is in the clause-initial position. Li and Zhang (1986) also indicate that the natural clause sequence in Chinese complex sentences is subordinate-to-main clauses ( $\mathrm{SC}-\mathrm{MC}$ ), although the salient and less common main-to-subordinate clause (MC- $\mathrm{SC}$ ) sequence is possible. Thus, we can find SC-MC as the unmarked order. However, example $2 \& 3$ are the English temporal adverbial clauses. Scollon (1993) revealed that when can be used in English in two ways. The unmarked structure is $X$ when $Y$, while the marked one is when $Y, X$. In the same case, we can find the characteristics of temporal adverbial clause proposed by conjunctions before and after in example4 to example9.

4) Ta shangban zhiqian xian du le baozhi.

He go to work before past tense read past tense newspaper.

5) Before he went to work, he read newspaper.

6) He read newspaper before he went to work.

7) Temen sou hou wo zai gaosu ni.

They leave after I tell you

8) After they leave, I will tell you.

9) I will tell you after they leave.

In addition, Chen Chunhua(2004), Guan yanhong(2006), Li Yinmei \& Wang Yina(2016) also revealed that English main clause tends to be put in the first place. What's more, from typological perspective, Chinese is a left-branching sentence, and English is a right-branching sentence, which can be reflected in attributive clause in these two languages. Therefore, the research of this paper is to explore whether 3 different groups would use the unmarked English MC-SC clause organization order in their L1 Chinese translation and writing. The following is to illustrate the methodology of the paper.

\section{B. Psycho-linguistic Pattern under Research}

Iconicity is concerned with sequencing information closely and Ungerer \& Schmid (1996) described the principle of Iconic Sequencing as "the sequence of two clauses corresponds with the nature rules (temporal order of events)"(p.251). Example 10) can be provided as follow,

10) She opened the door and lay on the bed.

11) * She lay on the bed and opened the door.

The sentence 10) can be accepted due to the natural rule, and sentence11) is syntactic right but cannot be accepted in principle of Iconic Sequencing, which violates the possible world. Clark (1977) claimed that sequential iconicity is best manifested in language development in children. Then Tai $(1985,1993)$ proposed the principle of Temporal Sequence which meant the order of the two syntactic units in complex sentence is determined by the temporal order of the states which they represent in the conceptual world. Like 10), we generally put 'and' or 'then' after the first event and before the second event in Chinese. However, we can use the sentence patterns like the following in English,

12) She opened the door before lying on the bed.

13) She lay on the bed after opening the door.

Sentence 12) and 13) can show that the normal clause order in English is not constrained by the sequence of events. The most typical example is like sentence 14),

14) You can't sleep until you finish your homework.

15) You finish your homework and then can sleep.

Sentence 15) is Chinese version to English sentence 14), from which we can see that Chinese linguistics word order corresponds to the temporal order of events unlike English. Therefore, with the regard of word order, Chinese is more iconic than English. On the basis of it, the linguistic patterns used to encode the conceptual principles may vary from culture to culture. 


\section{Sociolinguistic Pattern under Research}

Young (1982) showed that Chinese speakers tend to delay their topic until the supporting sentences have been given totally and Scollon(1991) argued that there exists confusion in intercultural communication often arises as a result of differing discursive strategies in the placement of the topic statement. The Chinese scholars, such as Li \& Wang (2015) claimed that Chinese is a topic salient language and the subordinate clause owns rich topicality and transitivity. The subordinate clause is put at the beginning as the background of topic. Chen (2006) illustrated that Chinese discourse convention is an inductive one, English discourse convention is a deductive one. Chinese need to use a considerable amount of words (small talk) to conform the politeness principle, which means small talk is valued as a type of face work to mitigate the imposition in the following topic statement. However, English usually put topic statement in the first place and followed by the supporting statement. All in all, The Chinese SC-MC sequence pattern aims to build a good interpersonal relationship, and then try to give the topic statement, but English MC-MC sequence pattern aims to give the topic statement firstly and base on the event. The difference can be due to different cultures and ways of thinking between Chinese and English.

\section{METHODOLOGY}

\section{A. Participants}

Three groups of subjects participated in this study, one group (group1) are Chinese Mainland undergraduates from University of Newcastle in Australia, the second group (group2) are Chinese mainland undergraduates from Hei Longjiang Bayi Agricultural University in China, they are majored in English; The last group (group3) are mother tongue reference group. The three groups can be composed of 180 participants. Group1 and group2 can be divided into 3 subgroups (levels), with 20 participants on each proficiency level. There are 60 participants in group1 and the same number in group2. Group3 can be made up of 60 participants. We set the first two groups as experimental groups and the third one as a controlled one. Specifically, group1 are undergraduates who have been staying in UoN for three years, they are studying in L2 environment; group2 are English major undergraduates who are in junior level; and group3 are baseline group for data comparison with EFL groups. Both group2 and group3 are from L1 environment. The proficiency level in group1 is divided on the basis of their IELTS scores. Level1 participants get IELTS scores over (equal) 7; level2 participants get IELTS scores in the range of 5.5-7; level3 participants get IELTS scores below 5.5 or don't pass the exam. The proficiency level in group2 is divided on the basis of their English scores in Test for English Major Band4 (TEM4). Level1 participants get English scores over 80; Level2 participants get English scores in the range of 70-79; Level3 participants get English scores in the range of 60-69.

\section{B. Instrument and Procedure}

Data for this study are collected from students completing their English-Chinese translation as well as writing essays which can be completed through several pictures. The translation exams contain 15 items in 3 types of conjunctions---when, before and after. Out of 15 test items, 5 ones focus on the conjunction of before, 5 ones focus on the conjunction of after, and 5 ones focus on the conjunction of when/while. For the essay task, the participants are intended to write a narrative of 100-120 words from eight sequential pictures, aiming for them to narrate the sequential pictures in order. During this, the participants need to use temporal adverbial clauses. They are given one hour to complete the two tasks.

Since there are two types of tasks, we manipulate both cautiously. Participants complete translation tasks before writing the essay. The translation test items are put in appendix 1 and the sequential pictures for essay writing are as follow:
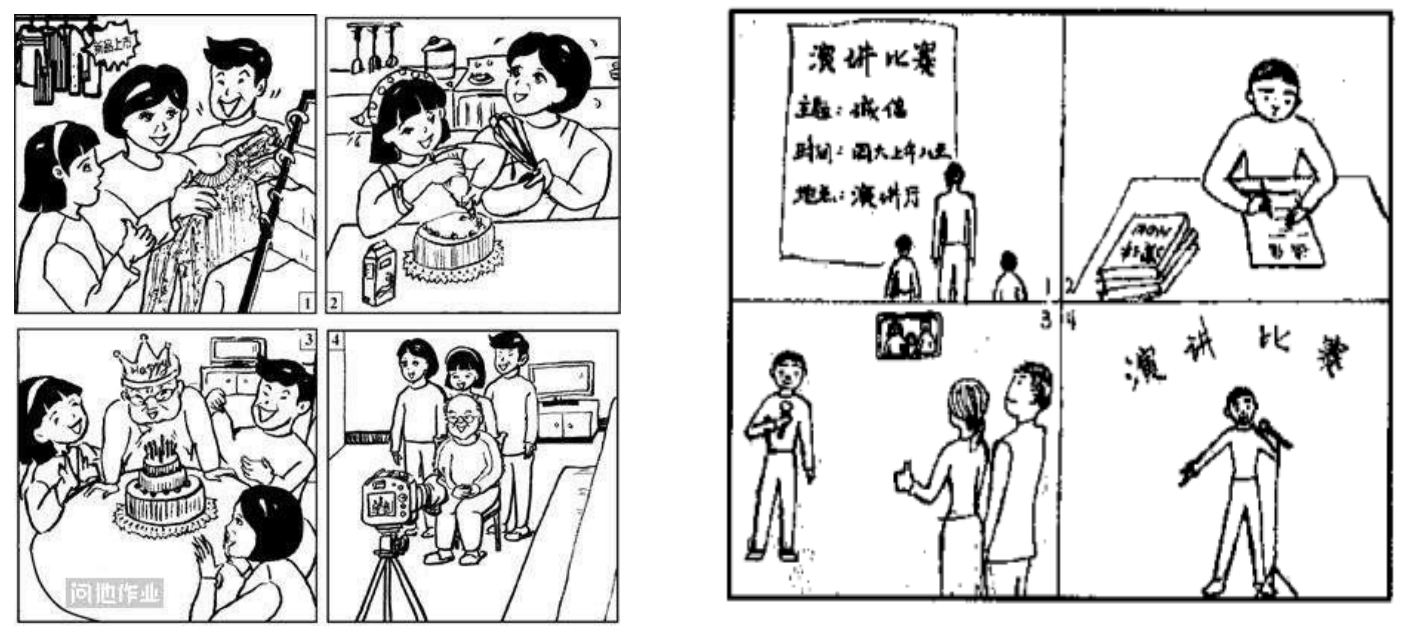


\section{RESULTS}

The two research questions are as follow: 1) Does their L2 have any effect on their L1 when the mainland Chinese EFL users are making temporal adverbial clause in their L1?

2) If indeed, does their L2 English proficiency have any effect on the degree of their L1 Chinese and if does, how does their L2 English proficiency level relate to backward transfer?

Based on previous study, L1 skills may decline in an L2 environment, it is hypothesized that L2 has some effect on L1 when students make temporal adverbial clauses. In addition, there is a relationship between L2 proficiency and the use of L1 clause pattern SC---MC (before/after/when/while..., ...) in the translation and essay writing tasks for mainland Chinese ESL learners. First of all, we can see the frequency distribution in the performance of the Chinese ESL learners on translation task across group1.

TABLE 1

\begin{tabular}{|l|l|l|l|l|l|}
\hline \multicolumn{4}{|l|}{ Participants } & \multicolumn{4}{|l|}{ Translation task } \\
\hline Clause pattern & After/before/when/while-middle & $11.7 \%$ & 13 & After/before/when/while-initial \\
\hline \multirow{3}{*}{ Group1 } & Level1 & 7 & $20 \%$ & 8 & $13.7 \%$ \\
\cline { 2 - 7 } & Level2 & 12 & $25 \%$ & 5 & $8.3 \%$ \\
\cline { 2 - 7 } & Level3 & 15 & $56.7 \%$ & 26 & $43.3 \%$ \\
\hline
\end{tabular}

As revealed by table1, group1 exhibits different use of After/before/when/while-initial at different proficiency levels in translation task. Generally discussing, temporal adverbials are put in the middle part more than the initials. Among it, level1 shows the vast contrast between the two parts. Level1 tends to put temporal adverbials in the initials. Gradually Level 3 can be found only $8.3 \%$ students put temporal adverbials in the initials. On the whole, Group1 tends to put temporal adverbials in the middle part. But the contrast is not severe. Temporal-initials and -middles lie in $43.3 \%$ and $56.7 \%$ respectively. The explanation is that to some extent group1 can be influenced by their L2 (English) word order. In addition, they have been staying in Australia for two years or so, English mode of expression plays an important role. However, students in high proficiency (Level1 in Group1) can mostly put temporal adverbials in the initials, which can prove the higher proficiency students are, the more capable of overcoming backward transfer from L2 (English) to L1 (Chinese).

TABLE 2

\begin{tabular}{|l|l|l|l|l|l|}
\hline \multicolumn{4}{|l|}{ Participants } & \multicolumn{4}{|c|}{ Translation task } \\
\hline Clause pattern & \multicolumn{1}{|l|}{ After/before/when/while-middle } & \multicolumn{2}{l|}{ After/before/when/while-initial } \\
\hline \multirow{3}{*}{ Group2 } & Level1 & 11 & $18.3 \%$ & 9 & $15 \%$ \\
\cline { 2 - 6 } & Level2 & 14 & $23.3 \%$ & 6 & $10 \%$ \\
\cline { 2 - 6 } & Level3 & 17 & $28.3 \%$ & 3 & $5 \%$ \\
\hline Chinese total & 42 & $70 \%$ & 18 & $30 \%$ \\
\hline
\end{tabular}

As revealed by table2, group2 exhibits different use of After/before/when/while-initial at different proficiency levels in translation task. Specifically, it is the same as Group1 that temporal adverbials are put in the middle part more than the initials. Among it, level1 shows the more students put it in the initial than level2 and level3. Level3 tends to put temporal adverbials in the middle. Level 3 can be found only $5 \%$ students put temporal adverbials in the initial. On the whole, the contrast is becoming clear. Temporal-initials and -middles lie in 30\% and $70 \%$ respectively. Although Group2 tends to put temporal adverbials in the middle, there are still more students in Level1 with the tendency to put temporal adverbial in the initial. It can indicate that the backward transfer can be found more in low level students from Chinese university.

Therefore, in terms of translation task, backward transfer can be totally found in Group1 and Group2, whereas it can be overcome to some extent with the higher proficiency level. The following part we will discuss essay writing task.

TABLE 3

\begin{tabular}{|c|c|c|c|c|c|}
\hline \multirow{2}{*}{\multicolumn{2}{|c|}{$\begin{array}{l}\text { Participants } \\
\text { Clause pattern }\end{array}$}} & \multicolumn{4}{|c|}{ Essay writing task } \\
\hline & & \multicolumn{2}{|c|}{ After/before/when/while-initial } & \multicolumn{2}{|c|}{ After/before/when/while-middle } \\
\hline \multirow[t]{3}{*}{ Group1 } & Level1 & 15 & $25 \%$ & 5 & $8.3 \%$ \\
\hline & Level2 & 13 & $21.7 \%$ & 7 & $11.7 \%$ \\
\hline & Level3 & 17 & $28.3 \%$ & 3 & $5 \%$ \\
\hline \multicolumn{2}{|c|}{ Chinese total } & 45 & $75 \%$ & 15 & $25 \%$ \\
\hline
\end{tabular}

As revealed by table3, group1 exhibits different use of After/before/when/while-initial at different proficiency levels in essay writing task. In general, temporal adverbials are put in the initial part more than the middles. Among it, level2 shows a little bit more students choose middle position to do the task. Level3 shows the vast contrast between these two 
positions. On the whole, Group1 tends to put temporal adverbials in the initial part. The contrast is absolutely severe. Temporal-initials and -middles lie in $75 \%$ and $25 \%$ respectively. Although Group 1 have been staying in Australia for two years, they still put temporal adverbials in initial position mostly. Therefore, backward transfer from L2 (English) to L1 (Chinese) occurs scarcely.

TABLE 4

\begin{tabular}{|c|c|c|c|c|c|}
\hline \multirow{2}{*}{\multicolumn{2}{|c|}{$\begin{array}{l}\text { Participants } \\
\text { Clause pattern }\end{array}$}} & \multicolumn{4}{|c|}{ Essay writing task } \\
\hline & & \multicolumn{2}{|c|}{ After/before/when/while-initial } & \multicolumn{2}{|c|}{ After/before/when/while-middle } \\
\hline \multirow[t]{3}{*}{ Group2 } & Level1 & 17 & $28.3 \%$ & 3 & $5 \%$ \\
\hline & Level2 & 14 & $23.3 \%$ & 6 & $10 \%$ \\
\hline & Level3 & 16 & $26.7 \%$ & 4 & $6.7 \%$ \\
\hline \multicolumn{2}{|c|}{ Chinese total } & 43 & $71.7 \%$ & 17 & $28.3 \%$ \\
\hline
\end{tabular}

As revealed by table4, group2 exhibits different use of After/before/when/while-initial at different proficiency levels in essay writing task. In general, the reflection is similar to group1. Among it, temporal adverbials are put in the initial part much more than the middles. Level2 shows the slightest contrast between the two positions. However, it cannot indicate Level 2 is more likely to put temporal adverbials in the middle. On the whole, Group2 tends to put temporal adverbials in the initial part. The contrast is still severe. Temporal-initials and -middles lie in $71.7 \%$ and $28.3 \%$ respectively. It is easy to explain that students make use of mother tongue to come up with their ideas or write essays. Although Group2 is in English department, they cannot escape from Chinese environment. Therefore, backward transfer from L2 (English) to L1 (Chinese) also occurs scarcely.

TABLE 5
\begin{tabular}{|l|l|l|l|l|}
\hline Participants & \multicolumn{4}{|c|}{ Essay writing task } \\
\hline Clause pattern & After/before/when/while-initial & After/before/when/while-middle \\
\hline Group3 (controlled one) & 57 & $95 \%$ & 3 & $5 \%$ \\
\hline
\end{tabular}

In general, we make a specific comparison between these three groups in terms of backward transfer in translation and writing tasks. The results are as follow,

\begin{tabular}{|l|l|l|l|l|}
\multicolumn{5}{|c|}{ TABLE 6 } \\
\hline Particip-ants & \multicolumn{1}{|c|}{ Translation task } & \multicolumn{2}{c|}{ Essay writing task } \\
\hline $\begin{array}{l}\text { Clause } \\
\text { pattern }\end{array}$ & $\begin{array}{l}\text { After/before/ } \\
\text { when/while-initial }\end{array}$ & $\begin{array}{l}\text { After/before/ } \\
\text { when/while-middle }\end{array}$ & /while-initial & $\begin{array}{l}\text { After/before/when/while-mi } \\
\text { ddle }\end{array}$ \\
\hline Group1 & $43.3 \%$ & $56.7 \%$ & $75 \%$ & $25 \%$ \\
\hline Group2 & $30 \%$ & $70 \%$ & $71.7 \%$ & $28.3 \%$ \\
\hline Group3 & & & $95 \%$ & $5 \%$ \\
\hline
\end{tabular}

From the two tasks, it is evident to illustrate that in translation task, students tend to choose temporal-middle, while they tend to put temporal adverbials in initial position in essay writing task, which can indicate that in input-output task, backward transfer occurs within all types of students; while in output task, backward transfer occurs scarcely whatever students are at home or abroad. The explanation is mainly that language and social environment can directly influence backward transfer.

\section{CONCLUSION}

The present study makes a contribution to the study of the influence of the L2 on the L1 by examining the backward transfer on the syntactic level. The findings of this study can be summarized as follows:

Firstly, a second language can have an unstable influence on the first language in L2 environment, which is accordance with the language task. And a second language might exert influence on the first language in L1 setting, especially when the exposure to L2 is intensive. However, in most cases, backward transfer can seldom happen in Group2 (L1 setting).

Secondly, there is a relationship between L2 proficiency and the use of L1 clause pattern SC---MC (before/after/when/while..., ...) in the translation and essay writing tasks for Mainland Chinese ESL learners. What's more, the relationship between L2 proficiency level and backward transfer is quite complicated. In particular, there is a tendency that the higher proficiency students are, the higher capability they overcome backward transfer.

\section{ApPENDiX. ENGLish-Chinese TransLation}

1) My father had left for Canada just before the letter arrived.

2) You can't do your homework while you're watching TV.

3) I'll go on with the work when I come back tomorrow.

4) I went to school after I finished my breakfast.

5) The young scientist had worked day and night for a long period of ten years before he succeeded in finding out the 
new elements in chemistry.

6) She turned off the light before she left the office.

7) Please clean the room after you read this book.

8) He was always trying out new ideas when he was a child.

9) Lin Tao came to see Jim while Jim was mending his bike.

10) He had learned English for three years before he went to London.

11) She fell asleep when/while she was reading the newspaper.

12) We went home after we had finished the work.

13) I'll write to you after I finish my work

14) Take the medicine before you go to bed.

15) The man called the police after being robbed.

\section{REFERENCES}

[1] Anderson, Roger W. (1983). Introduction: A language acquisition interpretation of Pidginization and creolization. Pidiginization and Creolization as Language Acquisition, ed. By R.W. Anderson, 309-339. Rowley: Newbury House.

[2] Barnett, S. M., \& Ceci, S. J. (2002). When and where do we apply what we learn? A taxonomy for far transfer. Psychological Bulletin, 128(4), 612-637.

[3] Berman, R.(1980). Postposing, lexical repetition and the like: A study in contrastive stylistics. Journal of Applied Linguistics 2:3-25.

[4] Carson and Kubanyiova (1994).Re - Envisioning the Roles, Tasks, and Contributions of Language Teachers in the Multilingual Era of Language Education Research and Practice. The Modern Language Journal, 100: 117-132.

[5] Cenoz, Jasone (2003). The intercultural style hypothesis: L1 and L2 interaction in requesting behavior. In Effects of the Second Language on the First. Vivian Cook (ed.), 62-80. Clevedon: Multilingual Matters.

[6] Chen Chunhua. (2004). Language attitudes of University students in China. International Proceedings of Economics Development \& Research, 68(16), 89-97.

[7] Chen F. J. (2006). Interplay between forward and backward transfer in L2 and L1 writing: The case of Chinese ESL learners in the U.S. Concentric: Studies in Linguistics, 32(1), 147-196.

[8] Clark, A., \& Trafford, J. (1995). Boys into modern languages: An investigation of the discrepancy in attitudes and performance between boys and girls in modern languages. Gender and Education, 7(3), 315-326.

[9] Cook, V. (2003). Introduction: The changing L1 in the L2 user's mind. In V. Cook (Ed.), Effects of the second language on the first (pp.1-18). Clevedon, United Kingdom: Multilingual Matters.

[10] Cook, V. (2007b). "Multi-competence: Black hole or wormhole for second language acquisition research". In Understanding second language process, Edited by: Han, Z. H. 16-26. Clevedon, UK: Multilingual Matters. InEd. pp.

[11] Cummins, J. (1996). Negotiating Identities: Education for Empowerment in A Diverse Society. Los Angeles: California Association for Bilingual Education.

[12] De Bot, Kees and Clyne, Michael G. (1989). Language reversion revisited. Study in Second Language Acquisition 11:167-177.

[13] Detterman, D. K. (1993). The case for the prosecution: Transfer as an epiphenomenon. In D. K.Detterman \& R. J. Sternbery (Eds.), Transfer on trial: Intelligence, cognition, and instruction (pp.1-24). Norwood, NJ: Ablex Publishing Company.

[14] Dewaele, J.-M., \& Pavlenko, A. (2002). Emotional Vocabulary in interlanguage. Language Learning, 52, $263-322$.

[15] Ellis, A. B. (2007). The influence of reasoning with emergent quantities on students' generalizations. Cognition and Instruction, 25(4), 439-478.

[16] Fred Jyun-gwang Chen. (2006). Interplay between Forward and Backward Transfer in L2 and L1 Writing: The Case of Chinese ESL Learners in the US. Studies in Linguistics, 32.1: 147-196.

[17] F. Ungerer, H. J. Schmid. (2008). An introduction to cognitive linguistics. Beijing: Foreign Language Teaching and Research Press \& Peason Education Limited.

[18] Greeno, J. G., Moore, J. L., \& Smith, D. R. (1993). Transfer of situated learning. In D. K. Detterman \& R. J. Sternberg (Eds.), Transfer on trial: Intelligence, cognition, and instruction (pp. 99-167).Norwood, NJ: Ablex Publishing Company.

[19] Guan yanhong. (2006). An Analysis of English Syntactic Ambiguity [J]. Journal of Sichuan International Studies University, 4, 81-84.

[20] Jacquelyn Schachter. (1976). Learner Intuitions of Grammatically, Language Learning Research Club, University of Michigan.

[21] Jarvis, S. (2003). "Probing the effects of the L2 on the L1: A case study". In Effects of the second language on the first, Edited by: Cook, V. 81-102. Clevedon, UK: Multilingual Matters. InEd.pp.

[22] Jyun-gwang Chen. (2006). A Contrastive Analysis of Information Sequencing in Chinese American and American Learners of Chinese, American Educational Research Journal, 30(3), 585-610.

[23] Kelso, J. A., \& Zanone, P. G. (2002). Coordination dynamics of learning and transfer across different effector systems. Journal of Experimental Psychology: Human Perception and Performance, 28(4), 776-797.

[24] Kubanyiova, M. (2006). Developing a motivational teaching practice in EFL teachers in Slovakia: Challenges of promoting teacher change in EFL contexts. TESL-EF, 10(2), 1-17.

[25] Laufer, B. (2003). Some properties of the foreign language learners' lexicon as evidenced by lexical confusions. International Review of Applied Linguistics in Language Teaching. Vol. 29, No. 4: 317-330.

[26] Li, N., \& Zhang, X. (2013). Literature review of the abroad studies on student engagement. Shanghai Research on Education, $12,22-26$.

[27] Li Yinmei \& Wang Yina. (2016). Markedness of Chinese and English Topic Constructions: A Cognitive Analysis Based on Spoken Corpus, Journal of Foreign Languages, 2016-06.

[28] Lobato, J., Rhodehamel, B., \& Hohensee, C. (2012). "Noticing" as an alternative transfer of learning process. The Journal for 
the Learning Sciences, 21(3), 433-482.

[29] Major, R.C. (1992). Losing English as a first language. The Modern Language Journal, 76, 190-208

[30] Marton, F. (2006). Sameness and difference in transfer. The Journal of the Learning Sciences, 15(4), 499-535.

[31] McLaughlin, B. (1987). Theories of Second Language Learning. London: Edward Arnold.

[32] Min Cao. (2016). Backward Pragmatic Transfer: An Empirical Study on Compliment Responses among Chinese EFL Learners. Theory and Practice in Language Studies, Vol. 6, No. 9, 1846-1854.

[33] Odlin, T. (1989). Language Transfer: Cross-Linguistic Influence in Language Learning. Cambridge: Cambridge University Press.

[34] Odlin, T. (2008). “Conceptual transfer and meaning extensions”. In Handbook of cognitive linguistics and second language acquisition, Edited by: Robinson, P. and Ellis, N. 306-340. New York, NY: Routledge. InEds.pp.

[35] Pavlenko, A. (2003). Bilingualism and emotions. Multilingua, 21, 45-78.

[36] P. Balcom. (1997). Why Is This Happened? Passive Morphology and Unaccusativity. Second Language Research, 13:1-29.

[37] Ramirez-Esparza. (2003). Social-Interactive Practices and Personality in Adult Learners of English with Little Formal Education. International Day of Multilingualism, 2 (62).

[38] Sarason, I. G. (1978). The test anxiety scale: Concept and research. In C. D. Spielberger \& I. G. Sarason (Eds.), Stress and anxiety (Vol. 5, pp. 193-216). Washington DC: Hemisphere.

[39] Schmidt, R. (1993). Awareness and second language acquisition. Annual Review of Applied Linguistics, 13(1), 206-226.

[40] Scollon, R., \& Scollon, S. W. (1995). Intercultural Communication A Discourse Approach. Oxford Basil Blackwell.

[41] Selinker, L. (1972). Interlanguage. International Review of Applied Linguistics, (10) 209-231.

[42] Su, I-R. (2003). Sentence processing transfer in Chinese EFL. Learners: a developmental perspective. In University of Hawaii Working Papers in Linguistics (pp. 109-126). Honolulu: University of Hawaii Press.

[43] Tai. (2003). The learning paradigm college. Boston: Anker.

[44] Ulrich Weinreich. (1953). Languages in Contact. Harvard: Harvard University Press.

[45] Valdes, Pino. (1981). Complement responses among Mexican-American bilinguals. Language in Society, 1 (61-63).

[46] Wagner, J. F. (2006). Transfer in pieces. Cognition and Instruction, 24(1), 1-71.

[47] Wagner, J. F. (2010). A transfer-in-pieces consideration of the perception of structure in the transfer of learning. Journal of the Learning Sciences, 19(4), 443-479.

[48] Wang, G. (2005). Humanistic approach and affective factors in foreign language teaching. Sino-US English Teaching, 2(5), 1-5.

[49] Young, D. J. (1999). Affect in foreign language and second language learning: A practical guide to creating a low-anxiety classroom atmosphere. Boston: McGraw-Hill.

[50] Zhang, Y. and Elder, C. (2011). Judgments of oral proficiency by non-native and native English speaking teacher raters: Competing or complementary constructs?. Language Testing, 28: 31-50.

Chen Yuan was born in Dunhua City, Jilin Province, China in 1986. He received his master degree in foreign and applied linguistics from Yanbian University, China in 2012.

He is currently a lecturer in the School of Humanity and Social Science, Hei Longjiang Bayi Agricultural University, Daqing, China. His research interests include language acquisition and teaching, cognitive linguistics.

Mr. Yuan has received first prize in Chinese national teaching contest. And he has been to University of Newcastle as a visiting scholar from 2017 to 2018. 